\title{
Neoliberalismo: ¿Historia para qué?
}

\author{
Neoliberalism: History for What?
}

\author{
Sandra Raggio-Ferrari ${ }^{1}$
}

\begin{abstract}
RESUMEN
El siguiente texto se propone reflexionar en torno a las políticas curriculares de los gobiernos neoliberales postdictaduras, en relación con la disciplina histórica. La hipótesis que se sostiene es que dichas políticas están asociadas al régimen de historicidad presentista propio de las sociedades neoliberales post caída del Muro de Berlín y no exclusivamente a políticas de olvido de la historia reciente.
\end{abstract}

Palabras claves: historia; memoria; currículum; neoliberalismo; dictadura.

\begin{abstract}
The following text is proposed to reflect on the curricular policies of post-dictatorship neoliberal governments, in relation to History. The hypothesis is these curricular policies are associated with the regime of present historicity typical of neoliberal societies after the fall of Berlin Wall, and not exclusively with forgetting policies of recent history.
\end{abstract}

Keywords: History; memory; curriculum; neoliberalism; dictatorship.

\footnotetext{
${ }^{1}$ Docente e investigadora de la Universidad Nacional de La Plata, Argentina. Directora general de la Comisión Provincial por la Memoria, provincia de Buenos Aires, Argentina; sanraggio@ hotmail.com.
} 
El debate surgido en Chile durante el año 2019 en torno a la reforma curricular propuesta por el gobierno de Sebastián Piñera, la cual, entre otras cuestiones, propone establecer la enseñanza de la Historia como asignatura optativa para los estudiantes del ciclo superior de enseñanza media, ha sido un debate también en Argentina durante los años noventa, en pleno auge del modelo neoliberal impulsado por el presidente Carlos Saúl Menem (1989-1999), en el marco de la reforma educativa llevada a cabo durante su gestión.

Las reformas curriculares impulsadas por los gobiernos neoliberales de ambos países, han puesto el foco en la Historia, intentando restringir su incidencia en el currículum. En Chile, la modalidad que adquirió la limitación de su presencia dentro de los contenidos enseñables fue su optatividad. En Argentina, la polémica se centró en torno a la desaparición de la disciplina dentro del currículum de los primeros años de la escuela secundaria, para fusionarse con Geografía, en la asignatura Ciencias Sociales. Al mismo tiempo, eliminaron de los contenidos la historia más antigua, para priorizar los periodos más recientes, en tanto aquellos eran considerados poco relevantes para ser transmitidos a las nuevas generaciones.

Tanto en Argentina como en Chile, la Historia, junto con la Educación Cívica, Lengua y Geografía, ha sido una de las disciplinas medulares en el proceso de consolidación de los estados nación, cuya función central estaba asociada a la construcción del imaginario sobre la nación y la comunidad nacional (Romero, 2004). Vale preguntarse, entonces, qué es lo que ha cambiado para que haya dejado de serlo, a pesar de que dentro de ese pasado a transmitir estén las dictaduras militares que constituyeron experiencias altamente significativas, con fuerte peso en el presente. ¿El objetivo es que las nuevas generaciones no sepan lo que pasó? ¿Es una explícita política de olvido?

Estas preguntas, aunque pertinentes, no permiten inscribir el problema en una indagación más amplia y compleja. En principio, debemos señalar que el auge del neoliberalismo a escala global -que ha declarado el "fin de la historia"- ha sido contemporáneo con el boom de las políticas de la memoria. En muchos países se han creado museos de la memoria y se han multiplicado las iniciativas sociales y estatales que recuerdan sucesos del pasado, anclados en experiencias de violencias extremas. No pareciera entonces que se trata lisa y 
ENSAYO: NEOLIBERALISMO ¿HISTORIA PARA QUÉ? / RAGGIO-FERRARI

llanamente de producir olvido. Es más, en la Argentina, el énfasis puesto en los periodos más recientes a ser enseñados, implicó que la dictadura cívico militar ingresara al currículum, lo que se expresó en la renovación de los manuales escolares para la enseñanza de la Historia y las Ciencias Sociales (Raggio, 2014).

Postularemos más bien que los gobiernos neoliberales sostienen que enseñar Historia no es central en la formación de las nuevas generaciones, puesto que esto se condice con el régimen de historicidad que los contiene: el presentismo.

El régimen de historicidad es la forma de articulación entre pasado, presente y futuro. Esta forma de articulación, define un orden de tiempo en cada época y moldea la percepción y experiencia del tiempo que tienen las sociedades. El régimen de historicidad presentista, tal como Hartog (2007) lo ha definido, es el propio de las sociedades neoliberales post caída del Muro de Berlín y su característica central es que pasado y futuro se condensan en el presente.

En las sociedades capitalistas actuales, la percepción social del tiempo es muy distinta de la del régimen de historicidad moderno, cuya noción de la historia era progresiva, sostenida en el mito prometeico. El hito fundante fue la Revolución Francesa. El futuro albergaba la promesa que venía a superar el pasado, con un claro sentido redentor.

Es decir, la idea en torno al uso de la Historia de los neoliberales de hoy, es muy distinta de la que acuñaron las burguesías liberales modernizadoras del siglo XIX, constituyendo un elemento relevante en la conformación de los estados-nación. La Historia, como disciplina, nace en momentos de su consolidación para construir el relato de la nación, del pasado común fundante de la comunidad nacional. Pierre Nora (1984) llamaba a esta Historia la "historiamemoria". Estaba ligada a la construcción de las identidades nacionales, con el objetivo de relativizar el poder de otras identidades portadoras de un sentido disruptivo con el orden burgués. Por ejemplo, las identidades de clase: antes que trabajador, eres francés, alemán, italiano (Hobsbwam, 2009). O en nuestros países, las identidades de los pueblos originarios: antes que mapuche, guaraní o huarpe, eres chileno o argentino. En aquellos tiempos, las burguesías liberales y los estados nación necesitaban de la Historia.

A diferencia de este régimen de historicidad moderno, nacido al calor de las revoluciones burguesas y de la promesa de un futuro mejor, el régimen de historicidad neoliberal 
REVISTA SABERES EDUCATIVOS, Nº 4, ENERO-JUNIO 2020

presentista se caracteriza por la desaparición de la utopía (Traverso, 2017). Fukuyama (1992) hablaba del fin de la Historia como consagración del triunfo del capitalismo y la democracia liberal por sobre el comunismo, que fue, sin dudas, la utopía moderna del siglo XX, Revolución Rusa mediante.

La caída del Muro de Berlín (1989), significó entonces el fin de una disputa en el seno del paradigma moderno, que se expresó en el fin de la Guerra Fría y el triunfo resonante del capitalismo y la democracia liberal. Y con ello, la muerte del futuro como promesa redentora, que anidaba la idea de la revolución como vía de transformación de la historia. El pasado se condensó en el presente. He aquí un régimen de historicidad cuya percepción del tiempo y de la experiencia se desarrolla en un presente continuo.

Esta percepción es generada en gran medida por la dinámica que el mercado capitalista ha adquirido en los últimos cuarenta años, con la crisis del estado de bienestar y el modelo keynesiano. Hoy en día el tiempo corre veloz y los futuros en instantes se transforman en presentes y estos en pasados, pero tan efímeros que pierden densidad; son los desechos del presente. Todo cambia permanentemente para no cambiar nada. Cambiamos celulares, cambiamos autos, cambiamos pautas de consumo. El tiempo es vertiginoso, los acontecimientos pasan unos tras otros y se desvanecen en los medios de comunicación.

El pasado, entonces, tiene presencia en el presente, como otra modalidad de consumo, sea como Historia o como memoria, pues esta nueva reconfiguración de las estructuras económicas y sociales a escala global ha desgarrado los marcos sociales de construcción y transmisión de la memoria colectiva: la clase, la comunidad nacional. Por ello, vemos emerger con fuerza las políticas de memoria, con sus museos, sus archivos, es decir, su patrimonio. El pasado entonces deja de ser experiencia transmisible para transformarse en patrimonio conservable, aunque esta no sea la única modalidad en que los procesos de memoria se despliegan, como veremos.

Volvamos ahora a las preguntas que dieron origen a la reflexión: ¿por qué el neoliberalismo pretendería desplazar a la Historia del lugar central en los dispositivos de construcción identitaria de la comunidad nacional? 
ENSAYO: NEOLIBERALISMO ¿HISTORIA PARA QUÉ? / RAGGIO-FERRARI

Pues parece simple, en el marco del régimen de historicidad presentista, ¿para qué vamos a enseñar Historia? ¿Para qué indagar sobre la historicidad del presente si no hay otro futuro posible?

Por eso, para el neoliberalismo la Historia no importa, por eso no es obligatoria, es optativa. Se puede elegir entre saber o no saber Historia, como cualquier producto en la góndola de un supermercado. Se trata de una operación ideológica profunda, que revela los alcances del proyecto neoliberal, al punto de no solo proponer un modelo económico y político, sino también un modelo de sujeto: individualista, deshistorizado, despolitizado, competente y flexible a las transformaciones permanentes que necesita el mercado.

Es por ello que los movimientos surgidos para defender la Historia en las aulas, en Chile y en los noventas en la Argentina, conscientes o no, son movimientos de resistencia al proyecto neoliberal. Así como lo son las demandas de políticas de memoria en relación con lo ocurrido durante las dictaduras militares y las múltiples experiencias y trabajos de memoria que se despliegan desde la sociedad civil. Frente a una memoria reificante y meramente patrimonial, se expresa otra, crítica, que recupera lo que Walter Benjamin (2008) ha denominado la memoria de los vencidos.

Si no hay enseñanza de la Historia, si no hay posibilidades de historización del presente, no hay posibilidades de un proyecto diferente al actual. Sin posibilidades de historizar el presente, soy un sujeto solo en tiempo presente, no un sujeto histórico, inscripto en el tiempo como parte de un grupo o comunidad que ha sido y será lo que la acción colectiva, social y política produzcan a través de decisiones conscientes y voluntarias. Por el contrario, la sociedad neoliberal ideal está compuesta por individuos cuya única posibilidad de modificar su vida radica en su capacidad de competencia con otros, y de mejorarla, a partir de ampliar su capacidad de consumo y goce personal, no del bienestar general y del acceso a derechos colectivos.

Un sujeto sin posibilidades de historizarse, de ser consciente de su lugar en el devenir del tiempo es un sujeto que está impedido de ejercer plenamente sus derechos, está condenado a deambular por los laberintos del presente, moviéndose en los limitados márgenes que el 
REVISTA SABERES EDUCATIVOS, Nº 4, ENERO-JUNIO 2020

sistema le ofrece, sin posibilidades de definir el proyecto de nación y de sociedad que desea para sí y para los otros.

Entonces, ¿qué rol le es asignado a la escuela aquí? Es el espacio donde las nuevas generaciones aprenden y adquieren herramientas para competir entre ellas y así ascender en la escala social, en función de los recursos que van administrando y que les permiten acceder al mercado laboral y al mercado de consumo en mejores condiciones. La educación, entonces, deja de ser un derecho para transformarse en un recurso más para la carrera de los individuos contra otros individuos.

Ahora, ¿qué implica todo lo anterior para las democracias? Las democracias neoliberales de nuestra región básicamente gobiernan la desigualdad. Y no van a gestionar el conflicto de la desigualdad si no es a través de la violencia. Esto es lo que está en discusión.

Esta violencia no irrumpe por efecto de las políticas de olvido que propician la repetición de la historia. El presente no es la repetición del pasado, por más que se le parezca en algunos rasgos. Es la consecuencia de los procesos de violencia que se dieron en el pasado y que transformaron la trama social y, con ella, la distribución del poder en la sociedad. El juego de las democracias neoliberales postdictatoriales es un juego donde los dados están cargados (Svampa, 2006) y los jugadores -los distintos sectores sociales con intereses contrapuestosno juegan en igualdad de condiciones.

Entonces, cuando discutimos acerca del rol de la enseñanza de la Historia en las democracias postdictatoriales, no solo estamos discutiendo acerca de contenidos, de la presencia o no de tales temas y periodos dentro del currículum obligatorio, estamos discutiendo qué democracia y qué sociedad queremos. Si queremos democracias neoliberales, habitadas por sujetos que ejercen su ciudadanía solo para poder elegir a sus gobernantes y después se retiran a la escena privada; o si queremos ciudadanos/as activos/as, comprometidos/as, sujetos de derecho, capaces de edificar un nuevo futuro. Porque este presente no es mejor que el pasado, ni tampoco es el mejor futuro posible. Vivimos en sociedades más desiguales que hace cuarenta años, con amplios sectores de la población excluidos de bienes esenciales y derechos básicos, con escasa posibilidad de gozar de una 
ENSAYO: NEOLIBERALISMO ¿HISTORIA PARA QUÉ? / RAGGIO-FERRARI

vida digna y feliz. Y los neoliberalismos realmente existentes prometen que aún puede ser peor.

Las subjetividades juveniles están atravesadas por las grandes transformaciones que se dieron en los últimos años respecto a las tecnologías de la comunicación y los vínculos interpersonales en la era digital, y eso va a tener fuertes consecuencias para las democracias y la política que vengan. La escuela es el único lugar donde podemos disputar esas subjetividades. La pregunta es ya vieja, pero debemos formularla una vez más: ¿la escuela es un dispositivo de reproducción de las ideologías dominantes o es un dispositivo que puede brindar herramientas para la emancipación? Esto es lo que está en discusión. Este paso que podría parecer menor, la Historia de materia obligatoria a materia optativa, lo que dice y transmite es que la Historia no sirve para mucho.

Sin embargo, la respuesta no debe ser solo la defensa de la obligatoriedad y reclamar más horas de Historia, simplemente. Tenemos que preguntarnos para qué enseñar esa historia a las nuevas generaciones. Si acaso solo queremos que repitan o queremos que el espacio en el aula sirva para problematizar esas subjetividades que portan los/as estudiantes y portamos nosotros/as como docentes. No se trata de enseñar algunos datos o procesos, de saber qué pasó o no en la dictadura militar, sino que se trata de ser capaces de historizar el presente y construir junto a los/as estudiantes y nuevas generaciones la historicidad del sujeto. Cuando enseñamos Historia, no enseñamos procesos históricos. Enseñamos a pensar históricamente. $\mathrm{Y}$ no es posible esa operación si no vamos a contrapelo del régimen de historicidad neoliberal. Lo que se pone en juego no es la transmisión de información, de datos o conocimiento. Lo que se pone en juego es la transmisión de la experiencia histórica, es decir, de la memoria.

No se trata de una memoria reificada, objeto de contemplación y consumo, que se mira, se recorre, se visita, sino de un trabajo de memoria, de elaboración, que ensancha temporalmente el espacio de la experiencia, permitiéndole a las nuevas generaciones conectar con las experiencias de las viejas generaciones y a estas con las nuevas demandas de los/as jóvenes, reponiendo el futuro como construcción colectiva e intergeneracional. 
REVISTA SABERES EDUCATIVOS, Nº 4, ENERO-JUNIO 2020

En este sentido, la enseñanza de la Historia debe inscribirse como parte de los procesos de memoria, incorporándole a estos la capacidad crítica del hacer historiográfico, sin borrar la dimensión política, social y subjetiva de estos procesos que se inscriben en la dimensión de la experiencia de los sujetos, en su praxis, no solo en sus capacidades racionales reflexivas.

Los procesos de memoria permiten el encuentro intergeneracional, abren espacios de construcciones solidarias y afiliaciones, atravesados por las multitemporalidades que habitan el presente: lo pasado como huella, el futuro como expectativa. Para las nuevas generaciones, es una oportunidad para su configuración identitaria, en tanto que las experiencias pasadas ofrecen nuevos elementos para su construcción y redefinición como sujetos, no ya meros habitantes de un presente que nunca cesa, sino como edificadores de la sociedad que vendrá, inscriptos en la trama de la historia. Para las viejas generaciones, también es una oportunidad de reconfiguración identitaria, alejadas de nociones nostálgicas que no permiten su inscripción en el presente, sino tan solo como la imagen congelada de los vencidos.

Este ensanchamiento temporal de la experiencia, implica recuperar la capacidad de proyectarse históricamente y que la incertidumbre por el futuro se convierta en posibilidad de transformación y de reconstrucción de nuevas utopías. Ya no tal vez las anunciadas, sino las que emerjan de esos futuros posibles que se albergan en el encuentro entre el pasado y el presente, entre las viejas y las nuevas generaciones, y también entre la historia y la memoria.

\section{Referencias}

Benjamin, W. (2008). Tesis sobre la historia y otros fragmentos, México D.F., México: UNAM.

Fukuyama, F. (1992). El fin de la historia y el último hombre. Barcelona, España: Planeta.

Hartog, F. (2007). Regímenes de historicidad: presentismo y experiencias del tiempo, México D.F., México: Universidad Iberoamericana A.C.

Hobsbwan, E. (2009). La Era del imperio 1875-1914. Buenos Aires, Argentina: Crítica. 
ENSAYO: NEOLIBERALISMO ¿HISTORIA PARA QUÉ? / RAGGIO-FERRARI

Nora, Pierre (Dir.). (1984). Les Lieux de Mémoire, 1: La République. París, Francia: Gallimard.

Raggio, S. (2014). Enseñar pasados que no pasan. En P. Flier (Ed.), Dilemas, apuntes y reflexiones teórico metodológicas para el abordaje de la historia reciente (pp. 84105). La Plata, Argentina: EDULP.

Romero, L. A (Ed.). (2004). La Argentina en la escuela. Buenos Aires, Argentina: Siglo XXI Editores.

Svampa, M. (2006, marzo). El golpe inauguró una forma atroz de desigualdad. Revista $\tilde{N}$, Clarín, (9), s/p. Recuperado de http://maristellasvampa.net/el-golpe-inauguro-unaforma-atroz-de-desigualdad/

Traverso, E. (2017). Políticas de la memoria en la era del neoliberalismo. Revista Aletheia, 7(14), p. 01-11. 